\title{
The evolution of primary hyperparathyroidism
}

Bruno Ferraz-de-Souza'

$\mathrm{P}$ rimary hyperparathyroidism (PHPT) is a common endocrine disorder known since the 1920s (1); during its near 100 years of history, however, PHPT has proven to be an ever-changing disease. Throughout the developed world, a shift in the presentation of PHPT has happened in the past decades, from cases with severe bone and kidney disease to asymptomatic individuals identified through routine serum calcium screening (2). Indeed, cases with osteitis fibrosa cystica have become a rarity, even in developing countries such as Brazil $(3,4)$, and young endocrinologists in training are sometimes baffled by the gravity of such cases and unsure about their outcome. In parallel with this trend for earlier recognition of PHPT, our understanding of its pathophysiology has also significantly advanced, mainly through the molecular characterization of parathyroid calcium sensing and proliferative pathways, allowing the identification of a genetic predisposition to PHPT (5). In this issue of Archives of Endocrinology and Metabolism, two case reports highlight important nuances of this continuously evolving disorder $(6,7)$.

Oliveira and cols. report a 60 year-old female patient with an orbital brown tumor that significantly regressed after resolution of PHPT (6). Notably, her primary complaint was of facial bone swelling (due to the growth of the brown tumor), while typical PHPT symptoms, such as polyuria, constipation and fatigue, went under-noticed. This is an important reminder of how individual perception of disease manifestations affects its recognition, substantiating how severe cases of PHPT might go unrecognized for some time, even in an era of pre-symptomatic diagnosis. It could be argued that if the diagnosis of PHPT had been made prior to the investigation of the nasal mass, imaging might have sufficed to establish the nature of the bony lesion as a brown tumor and to carefully monitor its evolution, potentially rendering a biopsy dispensable. The most important message of this report, however, is to document the regression of the brown tumor following the resolution of PHPT, a prognostic information that can comfort patients and physicians when dealing with severely symptomatic PHPT.

Considering that in severe PHPT the whole skeleton is under strong PTH stimulus, it is both fascinating and bemusing why brown tumors occur in certain areas. In the case reported by Oliveira, for example, despite all the evident bony involvement (salt and pepper skull, brown tumors), bone mass as assessed by DXA was perhaps disproportionately only mildly reduced (lowest T-score $=-2.8$ in lumbar spine, information for distal radius is lacking). While this could indicate that the patient had very good peak bone mass to begin with (and this is supported by her substantial bone mass recovery following resolution of PHPT), it might also suggest that specific predisposition to brown tumors exist in certain areas of the skeleton. Surprisingly little is known about local factors or somatic variants rendering a skeletal site more sus-

1 Endocrinologia/LIM-18, Hospital das Clínicas da Faculdade de Medicina da Universidade de São Paulo (HCFMUSP), São Paulo, SP, Brasil

Correspondence to: Bruno Ferraz-de-Souza Av. Dr. Arnaldo, 455, sala 3324 (LIM-18)

01246-903 - São Paulo, SP, Brasil bruno.ferraz@hc.fm.usp.br

Received on Oct/5/2015 Accepted on Oct/5/2015 DOI: 10.1590/2359-3997000000124 
ceptible to lytic lesions in PHPT. A molecular basis for extra-increased osteoclastic activation at such locations might be inferred from the study of non-PHPT related giant cell tumors of bone (GCTB), in which somatic chromosomal instability and overexpression of RANK pathway elements have been implicated $(8,9)$.

Favere and cols. also report a case of symptomatic PHPT presenting with brown tumors, but with a genetic twist (7). A 62 year-old female patient with bone pain, fatigue and weight loss was found to have both PHPT and neurofibromatosis type 1 (NFl), clinically diagnosed on the basis of café au lait spots and multiple neurofibromas. An atypical parathyroid adenoma was identified as the cause of PHPT, and the authors appropriately discuss the challenging histopathological distinction between parathyroid adenoma and carcinoma, a subject also explored by Oliveira and cols., reminding us that while severe PHPT cases may be more frequently associated with parathyroid carcinoma $(6,10)$, parathyroid adenomas can also present with severe bone disease.

It may be that the association of PHPT and neurofibromatosis in the case reported by Favere and cols. is purely coincidental; NFl, however, is no stranger to the endocrinologist due to its association with pheochromocytoma $(11,12)$. NFl is caused by mutations in neurofibromin (encoded by NFI), a negative regulator of the Ras signaling pathway (13), involved in the pathophysiology of several endocrinopathies and cancer, thus rendering a hypothetical genetic predisposition to further endocrine tumors very feasible. Moreover, bony dysplasia and osteoporosis are hallmarks of NF1, substantiating a bone environment potentially more prone to lytic lesions in the context of PHPT, as seen in this case. Considering that the advent of massively parallel sequencing techniques are resulting in a paradigm shift in the identification of predisposition to endocrine disorders $(14,15)$ and that the analysis of NFI is well established in the molecular investigation of pheochromocytoma (16), the association seen in this case should prompt further work to qualify NFI to the currently proposed list of candidate genes for molecular screening in PHPT (5).

Taken together, these two case reports serve to remind us that severely symptomatic PHPT still exists and our efforts for early clinical recognition need to be sustained. They also motivate deeper molecular exploration of predisposition to PHPT and particular manifestations such as brown tumors as a means of identifying mechanisms which might enable earlier case identification and improved personalized care.

Disclosure: no potential conflict of interest relevant to this article was reported.

\section{REFERENCES}

1. Bilezikian J. Approach to parathyroid disorders. In: Rosen CJ, editor. Primer on the Metabolic Bone Diseases and Disorders of Mineral Metabolism. 8th ed. Ames: Wiley-Blackwell \& American Society for Bone and Mineral Research; 2013. p. 537-42.

2. Silverberg SJ, Clarke BL, Peacock M, Bandeira F, Boutroy S, Cusano NE, et al. Current issues in the presentation of asymptomatic primary hyperparathyroidism: proceedings of the Fourth International Workshop. J Clin Endocrinol Metab. 2014;99(10):3580-94.

3. Eufrazino C, Veras A, Bandeira F. Epidemiology of Primary Hyperparathyroidism and its Non-classical Manifestations in the City of Recife, Brazil. Clin Med Insights Endocrinol Diabetes. 2013;6:69-74.

4. Bandeira F, Griz L, Chaves N, Carvalho NC, Borges LM, LazarettiCastro $\mathrm{M}$, et al. Diagnosis and management of primary hyperparathyroidism--a scientific statement from the Department of Bone Metabolism, the Brazilian Society for Endocrinology and Metabolism. Arq Bras Endocrinol Metabol. 2013;57(6):406-24.

5. Eastell R, Brandi ML, Costa AG, D'Amour P, Shoback DM, Thakker RV. Diagnosis of asymptomatic primary hyperparathyroidism: proceedings of the Fourth International Workshop. J Clin Endocrinol Metab. 2014;99(10):3570-9.

6. Oliveira FM, Makimoto TE, Scalissi NM, Marone MM, Maeda SS. Regression of orbital brown tumor after surgical removal of parathyroid adenoma. Arch Endocrinol Metab. 2015;59(5):455-9.

7. Favere AM, Tsukumo DM, Matos PS, Santos SL, Lalli CA. Association between atypical parathyroid adenoma and neurofibromatosis. Arch Endocrinol Metab. 2015;59(5):460-5.

8. Moskovszky L, Dezso K, Athanasou N, Szendroi M, Kopper L, Kliskey $\mathrm{K}$, et al. Centrosome abnormalities in giant cell tumour of bone: possible association with chromosomal instability. Mod Pathol. 2010;23(3):359-66.

9. Skubitz KM, Cheng EY, Clohisy DR, Thompson RC, Skubitz AP. Gene expression in giant-cell tumors. J Lab Clin Med. 2004;144(4):193-200.

10. Ohe MN, Santos RO, Hojaij F, Neves MC, Kunii IS, Orlandi D, et al. Parathyroid carcinoma and hungry bone syndrome. Arq Bras Endocrinol Metabol. 2013;57(1):79-86.

11. Walther MM, Herring J, Enquist E, Keiser HR, Linehan WM. von Recklinghausen's disease and pheochromocytomas. J Urol. 1999;162(5):1582-6.

12. Amar L, Bertherat J, Baudin E, Ajzenberg C, Bressac-de Paillerets $B$, Chabre O, et al. Genetic testing in pheochromocytoma or functional paraganglioma. J Clin Oncol. 2005;23(34):8812-8.

13. Schubbert S, Shannon K, Bollag G. Hyperactive Ras in developmental disorders and cancer. Nat Rev Cancer. 2007;7(4):295-308.

14. Forlenza GP, Calhoun A, Beckman KB, Halvorsen T, Hamdoun E, Zierhut $\mathrm{H}$, et al. Next generation sequencing in endocrine practice. Mol Genet Metab. 2015;115(2-3):61-71.

15. de Bruin C, Dauber A. Insights from exome sequencing for endocrine disorders. Nat Rev Endocrinol. 2015;11(8):455-64.

16. Dahia PL. Pheochromocytoma and paraganglioma pathogenesis: learning from genetic heterogeneity. Nat Rev Cancer. 2014;14(2):108-19. 